\title{
UJI EFEKTIVITAS TEKNIK RELAKSASI, SENAM POMPA JANTUNG DAN PENGUATAN OTOT PERUT TERHADAP PENURUNAN NYERI MENSTRUASI
}

\author{
Enny Fitriahadi ${ }^{1}$
}

\author{
${ }^{1}$ Program Studi D-IV Bidan Pendidik STIKES 'Aisyiyah Yogyakarta \\ E-mail : ennyfitriahadi@rocketmail.com
}

\begin{abstract}
Background: Dysmenorrhea is menstruation pain commonly experienced by female adolescents. This problem is caused by progesterone imbalance in the blood, prostaglandins and stress/psychology factors. It affects on at least $50 \%$ of women in reproductive age and $60-85 \%$ of female teenagers.

Objective: This study aimed to investigate the effectiveness of relaxation techniques, heart pump exercise and strengthening the abdominal muscles to decrease menstrual pain in the second semester students of STIKES 'Aisiyah Yogyakarta in 2015.
\end{abstract}

Methods: This was quantitative research with quasy experimental design with nonequivalent control group. Samples were selected using simple random sampling. The samples in this study were 60 female students. Analysis of the data used Kendall's Tau.

Result: The findings showed that relaxation techniques together with heart pumping exercises provide lower effectiveness in reducing menstrual pain with $p$-value of 0.059 . Whereas, relaxation techniques, heart pumping exercise and abdominal muscles strengthening showed relationship with $p$-value of 0.035 .

Conclusion: Relaxation techniques, heart pumping exercise and abdominal muscles strengthening are effective in reducing menstrual pain.

Keyword: decrease menstrual pain, relaxation techniques, exercise cardiac pump, strengthening abdominal muscles

\section{PENDAHULUAN}

Menstruasi adalah perubahan fisiologi dalam tubuh wanita yang terjadi secara berkala dan dipengaruhi oleh hormon reproduksi baik $\mathrm{FSH}$-Estrogen atau $\mathrm{LH}$ Progesteron. Periode ini penting dalam hal reproduksi. Hal ini biasanya terjadi setiap bulan antara usia remaja sampai menopause.

Menstruasi dialami saat pubertas dan kemampuan seorang wanita untuk mengandung anak atau masa reproduksi. Menstruasi biasanya dimulai antara usia 10 dan 16 tahun, tergantung pada berbagai faktor, termasuk kesehatan wanita, status nutrisi, dan berat tubuh relatif terhadap tinggi tubuh. Walaupun begitu, pada kenyataannya banyak wanita yang mengalami masalah menstruasi, di antaranya nyeri haid atau dismenore. $^{(1)}$

\section{Menurut}

Faizah

dalam

Annathayakheisha $^{(2)}$ dismenore merupakan nyeri yang dialami remaja saat menstrusi. Dismenore disebabkan ketidakseimbangan hormon progesteron dalam darah, prostaglandin, dan faktor stres/psikologi mengakibatkan terjadinya dismenore pada beberapa wanita. Nyeri haid sering dialami oleh sebagian besar wanita. Dari data yang didapat, dismenore ini mengganggu setidaknya $50 \%$ wanita masa reproduksi dan $60-85 \%$ pada usia remaja, yang mengakibatkan banyaknya absensi pada sekolah maupun kantor. Untuk mengatasi hal tersebut sebagian wanita menggunakan obat yang berfungsi secara kuratif. Dalam penelitian akan memberikan alternatif terapi 
yang sederhana, mudah dilakukan, dan bersifat preventif.

Berdasarkan gambaran tentang masalah nyeri menstruasi yang sering dialami oleh para remaja pada umumnya peneliti tertarik untuk melakukan penelitian dengan tujuan untuk mengetahui keefektifan teknik relaksasi, senam pompa jantung dan penguatan otot perut terhadap penurunan nyeri menstruasi pada mahasiswi semester II D-IV Bidan Pendidik Stikes 'Aisyiyah Yogyakarta.

Tujuan umum penelitian ini adalah utuk mengetahui uji efektivitas teknik relaksasi, senam pompa jantung, dan peguatan otot perut terhadap penurunan nyeri menstruasi.

\section{BAHAN DAN CARA PENELITIAN}

Penelitian ini menggunakan rancangan kuantitatif dengan metode quasy experimental design atau eksperimen semu dengan desain nonequivalent control group design yaitu membandingkan antara kelompok mahasiswi yang melakukan teknik relaksasi, senam pompa jantung, dan penguatan otot perut terhadap penurunan nyeri menstruasi dengan kelompok kontrol yaitu mahasiswi yang hanya melakukan teknik relaksasi dan senam pompa jantung terhadap penurunan nyeri menstruasi di Stikes 'Aisyiyah Yogyakarta Tahun 2015. Populasi pada penelitian ini adalah seluruh mahasiswi Prodi D-IV Semester II Stikes 'Aisyiyah Yogyakarta. Sampel dalam penelitian ini adalah 60 responden yang memiliki kriteria inklusi yang kemudian dibagi menjadi dua kelompok yaitu 30 mahasiswi yang hanya diberi perlakuan teknik relaksasi dan senam pompa jantung dan 30 mahasiswi yang diberi perlakuan teknik relaksasi, senam pompa jantung dan penguatan otot perut. Pengukuran nyeri menstruasi pada penelitian ini menggunakan lembar observasi dengan menggunakan skala nyeri Wong Baker yang diukur sebelum dilakukan perlakuan dan sesudah dilakukan perlakuan. Perlakukan ini dilakukan selama dua hari berturut-turut. Analisis data yang diguunakan dalam penelitian ini menggunakan Kendal Tau. ${ }^{(3)}$

\section{HASIL DAN PEMBAHASAN}

Penelitian ini sudah mendapatkan izin dari komisi etik Stikes 'Aisyiyah Yogyakarta.

\section{Tabel 1. Distribusi Frekuensi Karakteristik Responden Berdasarkan Usia No Usia Frekuensi Presentase} (f) (\%)

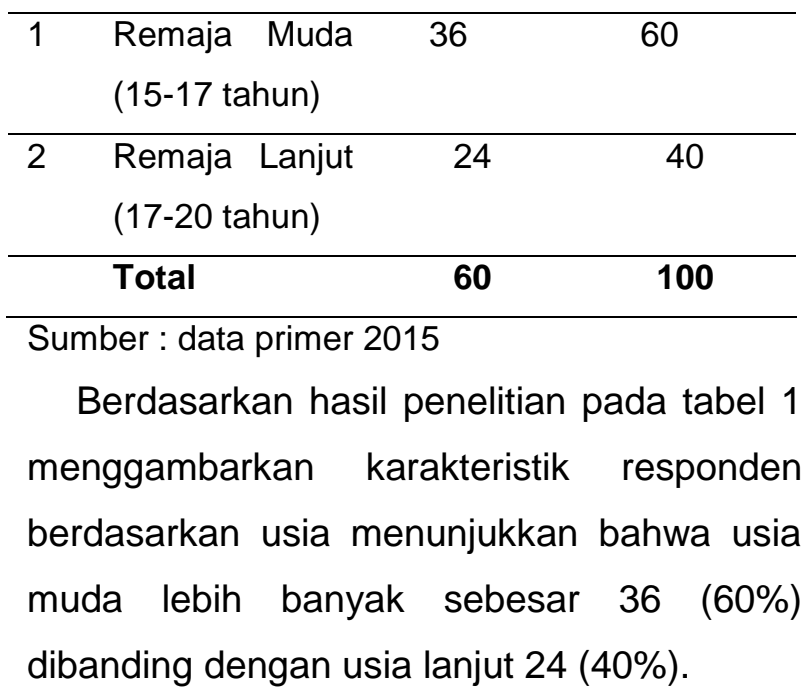


Tabel 2. Distribusi Frekuensi Teknik

Relaksasi, Senam Pompa Jantung dan

Penguatan Otot Perut

\begin{tabular}{llcc}
\hline No & Perlakuan & $\begin{array}{c}\text { Frekuensi } \\
\text { (f) }\end{array}$ & $\begin{array}{c}\text { Prosentase } \\
\text { (\%) }\end{array}$ \\
\hline 1 & $\begin{array}{l}\text { Teknik } \\
\text { relaksasi dan }\end{array}$ & 30 & 50 \\
& $\begin{array}{l}\text { senam pompa } \\
\text { jantung }\end{array}$ & \\
\hline 2 & $\begin{array}{l}\text { Teknik } \\
\text { relaksasi , }\end{array}$ & & \\
& $\begin{array}{l}\text { senam pompa } \\
\text { jantung, dan } \\
\text { penguatan otot } \\
\text { perut }\end{array}$ & \\
\hline & & \\
\hline
\end{tabular}

Sumber : Data primer 2015

Tabel 3. Distribusi Frekuensi Nyeri Menstruasi

Mahasiswi Semester II D-IV Bidan Pendidik

Stikes 'Aisyiyah Yogyakarta

\begin{tabular}{llcc}
\hline No & \multicolumn{1}{c}{$\begin{array}{c}\text { Nyeri } \\
\text { Menstruasi }\end{array}$} & $\begin{array}{c}\text { Frekuensi } \\
(\mathbf{f})\end{array}$ & $\begin{array}{c}\text { Persentase } \\
(\%)\end{array}$ \\
\hline 1 & Sedikit sakit & 5 & 8,3 \\
\hline 2 & $\begin{array}{l}\text { Agak } \\
\text { mengganggu }\end{array}$ & 41 & 68,3 \\
\hline 3 & $\begin{array}{l}\text { Mengganggu } \\
\text { aktivitas }\end{array}$ & 4 & 6,6 \\
\hline 4 & $\begin{array}{l}\text { Sangat } \\
\text { mengganggu }\end{array}$ & 7 & 11,6 \\
\hline 5 & $\begin{array}{l}\text { Tidak } \\
\text { tertahankan }\end{array}$ & 3 & 5 \\
\hline Total & $\mathbf{6 0}$ & $\mathbf{1 0 0}$ \\
\hline Berdasarkan hasil penelitian pada & tabel 3,
\end{tabular}

terlihat bahwa mahasiswi yang mengalami nyeri menstruasi sedikit sakit sebanyak 5 (8,3\%), agak mengganggu 41 (68,3\%), mengganggu aktivitas 4 (6,6\%), sangat mengganggu 7 (11,6\%), sedangkan tidak tertahankan 3 (5\%).

Tabel 4. Keefektifan Teknik Relaksasi dan

Senam Pompa Jantung Terhadap Nyeri Menstruasi

\begin{tabular}{lcccc}
\hline \multirow{1}{*}{$\begin{array}{c}\text { Nyeri } \\
\text { Menstruasi }\end{array}$} & \multicolumn{4}{c}{$\begin{array}{c}\text { Perlakuan Teknik Relaksasi dan Senam } \\
\text { Pompa Jantung }\end{array}$} \\
\cline { 2 - 5 } & $\begin{array}{c}\text { Sebelum } \\
\text { Perlakuan }\end{array}$ & $\%$ & $\begin{array}{c}\text { Sesudah } \\
\text { Perlakuan }\end{array}$ & $\%$ \\
\hline Sedikit sakit & 2 & 6,6 & 19 & 63,3 \\
\hline $\begin{array}{l}\text { Agak } \\
\text { mengganggu }\end{array}$ & 21 & 70 & 8 & 26,6 \\
\hline $\begin{array}{l}\text { Mengganggu } \\
\text { aktivitas }\end{array}$ & 2 & 6,6 & 1 & 3,3 \\
\hline $\begin{array}{l}\text { Sangat } \\
\text { mengganggu }\end{array}$ & 4 & 13, & 1 & 3,3 \\
\hline $\begin{array}{l}\text { Tidak } \\
\text { tertahankan }\end{array}$ & 1 & 3 & & \\
\hline
\end{tabular}

\begin{tabular}{|c|c|c|c|c|}
\hline Total & 30 & 100 & 30 & 100 \\
\hline
\end{tabular}

tabel 4 menunjukkan bahwa perlakuan dengan teknik relaksasi dan senam pompa jantung sebelum perlakuan yang mengalami nyeri menstruasi sedikit sakit ada 2 (6,6\%), agak mengganggu 21 (70\%), mengganggu aktivitas $2(6,6)$, sangat mengganggu 4 $(13,3 \%)$, tidak tertahankan 1 (3,3\%) sedangkan sesudah perlakuan nyeri menstruasi sedikit sakit ada 19 (63,3\%), agak mengganggu 8 (26,6\%), mengganggu aktivitas $1(3,3)$, sangat mengganggu 1 $(3,3 \%)$, tidak tertahankan $1(3,3 \%)$.

Tabel 5. Keefektifan Teknik Relaksasi, Senam Pompa Jantung dan Penguatan Otot Perut Terhadap Nyeri Mesntruasi

\begin{tabular}{lccc}
\hline \multicolumn{1}{c}{ Korelasi } & N & $\begin{array}{c}\text { Nilai } \\
\text { Signifikansi }\end{array}$ & $\begin{array}{c}\text { Koefisien } \\
\text { Korelasi }\end{array}$ \\
\hline Perlakuan & 30 & 0,549 & 0,102 \\
Teknik & & & \\
Relaksasi dan & & & \\
Senam Pompa & & & \\
Jantung & & & \\
\hline
\end{tabular}


Berdasarkan hasil penelitian pada tabel 5 diketahui perlakuan dengan teknik relaksasi, senam pompa jantung dan penguatan otot perut sebelum perlakuan yang mengalami nyeri menstruasi sedikit sakit ada 3 (10\%), agak mengganggu 20 (66,6\%), mengganggu aktivitas $2(6,6)$, sangat mengganggu 3 (10\%), tidak tertahankan $2(6,6 \%)$ sedangkan sesudah perlakuan nyeri menstruasi sedikit sakit ada 23 (76,6\%), agak mengganggu 5 (16,6\%), mengganggu aktivitas $2(6,6)$, sangat mengganggu 0 , tidak tertahankan 0 .

Temuan ini sesuai dengan hasil penelitian Kurnia ${ }^{(4)}$ yang mengatakan bahwa nyeri menstruasi dapat berkurang apabila dilakukan perlakuan atau tindakan asuhan kebidanan dengan senam dan massage pada daerah punggung. Hal tersebut mengandung makna bahwa wanita yang sedang mengalami nyeri menstruasi, nyeri menstruasi bisa berkurang apabila dilakukan asuhan kebidanan yang tepat seperti teknik relaksasi, senam pompa jantung dan penguatan otot perut. Sesungguhnya Allah menyukai orang-orang yang berusaha.

Tabel 6. Hasil Uji Keefektifan Teknik Relaksasi dan Senam Pompa Jantung Terhadap Nyeri Menstruasi

\begin{tabular}{|c|c|c|c|c|}
\hline \multirow[t]{2}{*}{$\begin{array}{c}\text { Nyeri } \\
\text { Menstruasi }\end{array}$} & \multicolumn{4}{|c|}{$\begin{array}{l}\text { Perlakuan Teknik relaksasi, senam } \\
\text { pompa jantung dan penguatan otot } \\
\text { perut }\end{array}$} \\
\hline & $\begin{array}{l}\text { Sebelum } \\
\text { Perlakua } \\
\text { n }\end{array}$ & $\%$ & $\begin{array}{c}\text { Sesudah } \\
\text { Perlakuan }\end{array}$ & $\%$ \\
\hline Sedikit sakit & 3 & 10 & 23 & $\begin{array}{c}76, \\
6\end{array}$ \\
\hline $\begin{array}{l}\text { Agak } \\
\text { mengganggu }\end{array}$ & 20 & 66,6 & 5 & $\begin{array}{c}16, \\
6 \\
\end{array}$ \\
\hline
\end{tabular}

\begin{tabular}{lcccc}
\hline $\begin{array}{l}\text { Mengganggu } \\
\text { aktivitas }\end{array}$ & 2 & 6,6 & 2 & 6,6 \\
\hline $\begin{array}{l}\text { Sangat } \\
\text { mengganggu }\end{array}$ & 3 & 10 & 0 & 0 \\
\hline $\begin{array}{l}\text { Tidak } \\
\text { tertahankan }\end{array}$ & 2 & 6,6 & 0 & 0 \\
\hline Total & $\mathbf{3 0}$ & $\mathbf{1 0 0}$ & $\mathbf{3 0}$ & $\mathbf{1 0 0}$ \\
\hline
\end{tabular}

Berdasarkan tabel 6. hasil uji Kendal Tau menunjukkan bahwa keefektifan teknik relaksasi dan senam pompa jantung pada mahasiswi didapatkan hasil p 0,549 (karena $\mathrm{p}$ value $>0,05)$ maka Ho diterima dan $\mathrm{Ha}$ ditolak yang artinya tidak ada keefektifan teknik relaksasi dan senam pompa jantung terhadap nyeri menstruasi. Hal ini sejalan dengan teori Faizah dalam Annathayakheisha $^{(2)}$ bahwa Dismenore adalah nyeri di perut bagian bawah ataupun di pungung bagian bawah akibat dari gerakan rahim yang meremas-remas (kontraksi) dalam usaha untuk mengeluarkan lapisan dinding rahim yang terlepas). Wanita pernah mengalami dismenore sebanyak 90\%. Masalah ini setidaknya mengganggu 50\% wanita masa reproduksi dan $60-85 \%$ pada usia remaja, yang mengakibatkan banyaknya absensi pada sekolah maupun kantor. Pada umumnya $50-60 \%$ wanita di antaranya memerlukan obat-obatan analgesik untuk mengatasi masalah dismenore ini.

Menurut Smeltzer ${ }^{(5)}$ penyebab nyeri haid ada beberapa faktor yaitu sebagai berikut Terjadinya konstraksi rahim atau iskemia otot rahim dikarenakan lepasnya dinding rahim akibat peningkatan prostaglandin. Nyeri haid atau dismenorrhoe adalah nyeri kejang otot (spasmodik) di perut 
bagian bawah dan menyebar ke sisi dalam paha atau bagian bawah pinggang yang terjadi menjelang haid atau selama haid akibat kontraksi otot rahim. Faktor hormonal karena nyeri haid diduga terkait dengan produksi hormon progesteron yang meningkat. Hormon progesteron dihasilkan oleh jaringan ikat kelenjar indung telur (corpus luteum) setelah melepaskan sel telur matang setiap bulan. Hormon tersebut memperbesar ketegangan mulut rahim hingga lubang mulut rahim menjadi sempit, akibatnya otot-otot rahim lebih kuat berkontraksi untuk dapat mengeluarkan darah haid melalui mulut rahim yang sempit. Kontraksi otot rahim yang menyebabkan kejang otot yang dirasakan sebagai nyeri. Keluhan nyeri haid berkurang atau malahan hilang setelah kehamilan atau melahirkan anak pertama. Hal ini karena regangan pada waktu rahim membesar dalam kehamilan membuat ujung-ujung syaraf di rongga panggul dan sekitar rahim menjadi rusak. Psikis atau kecemasan berlebihan karena emosi wanita sering susah ditebak. Kadang kala begitu tegar menghadapi berbagai masalah dan cobaan namun kali lain begitu rapuh menghadapi masalah yang sepele saja.

Tabel 7. Keefektifan Teknik Relaksasi, Senam

Pompa Jantung dan Penguatan Otot Perut Terhadap Nyeri Menstruasi

\begin{tabular}{cccc}
\hline Korelasi & N & $\begin{array}{c}\text { Nilai } \\
\text { Signifikasi }\end{array}$ & $\begin{array}{c}\text { Koefisien } \\
\text { Korelasi }\end{array}$ \\
\hline Teknik Relaksasi, & 30 & 0,035 & 0,350 \\
Senam Pompa & & & \\
Jantung, dan & & & \\
\hline
\end{tabular}

Penguatan Otot

Perut

Berdasarkan tabel 7. Hasil uji Kendal

Tau menunjukkan bahwa keefektifan teknik relaksasi, senam pompa jantung dan penguatan otot perut didapatkan hasil $p$ 0,035 (karena $p$ value $<0,05$ ) maka Ho ditolak dan $\mathrm{Ha}$ diterima yang artinya ada keefektifan teknik relaksasi, senam pompa jantung, dan penguatan otot perut terhadap nyeri menstruasi.

Prosedur perlakuan dari teknik relaksasi, senam pompa jantung, dan penguatan otot perut dilakukan selama 2 hari yang dilakukan sebanyak minimal 2 kali sehari. Sebelum perlakuan dilakukan mahasiswi diminta mengisi lembar observasi nyeri menstruasi menurut Wong Baker. Setelah mengisi mahasiswi diberikan perlakuan secara kombinasi dari teknik relaksasi, senam pompa jantung, dan penguatan otot perut, mahasisiwi tidur terlentang dengan sikap relaks dan anatomi kemudian mahasiswi melakukan gerakan relaksasi dengan menghirup udara dari hidung dan menghembuskan lewat mulut, kemudian salah satu kaki di tekuk dan kaki yang lain diangkat kurang lebih $15 \mathrm{~cm}$ dalam keadaan fleksi secara bersamaan kencangkan otot perut bagian bawah dengan hitungan 1-4 kaki diangkat, hitungan 5-8 kaki diturunkan secara perlahan-lahan. Kemudian bergantian dengan kaki yang lain, gerakan ini dilakukan sebanyak 8 kali. Setelah selesai melakukan perlakuan selama 2 hari mahasiswi diminta untuk mengisi lembar 
observasi yang sama lalu lingkari skala nyeri menstruasi menurut Wong Baker. ${ }^{(6)}$

Mekanisme dari perlakuan teknik relaksasi, senam pompa jantung, dan penguatan otot perut ini yaitu dengan melakukan perlakuan ini thalamus akan memerintahkan hipotalamus untuk menurunkan hormon stresor dan akan meningkatkan hormon relaksin, dengan meningkatnya hormon relaksin akan membantu melancarkan peredaran darah sehingga nyeri menstruasi akan berkurang. ${ }^{(7)}$

Berdasarkan hasil uji dan analisis penelitian ini dapat disimpulkan bahwa teknik relaksasi, senam pompa jantung, dan penguatan otot perut efektif untuk mengurangi nyeri mestruasi pada mahasiswi semester II D-IV bidan pendidik Stikes 'Aisyiyah Yogyakarta

\section{KESIMPULAN}

Berdasarkan hasil analisis data dan pengujian hipotesis dapat disimpulkan bahwa perlakuan teknik relaksasi dan senam pompa jantung kurang memberikan keefektifan dengan $p 0,059$ sedangkan perlakuan teknik relaksasi, senam pompa jantung, dan penguatan otot perut menunjukkan hubungan keeratan korelasi dengan $p \quad 0,035$ yang artinya ada keefektifan teknik relaksasi, senam pompa jantung, dan penguatan otot perut terhadap nyeri menstruasi.

\section{KEPUSTAKAAN}

1. Sumudarsono. Fisiologi Menstruasi. http://bidanku.com/mengenal-siklusmenstruasi. Diakses 21 November 2014; 1998.

2. Annathayakheisha dalam Faizah. Masalah-Masalah Dalam Menstruasi. www.info-kes.com/2013/05/masalah-haidmenstruasi.html. Diakses 21 November $2014 ; 2009$.

3. Arikunto, S. Prosedur Penelitian : Suatu Pendekatan Praktek. Edisi IV. Jakarta: Rineka Cipta; 2006.

4. Kurnia, A. Pengaruh Massage Terhadap Nyeri Haid Pada Remaja di Pondok Pesantren Putri Al Munawwir Komplek Nurussalam Krapyak Yogyakarta; 2011.

5. Smeltzer, Suzanne C. Keperawatan Medikal Bedah Brunner dan Suddart. Edisi 8, Vol 2. Jakarta : Buku kedokteran; 2002.

6. Revina. Skala Nyeri Wong Baker Face. Cara Mengatasi Nyeri Saat Menstruasi http://bidanku.com/cara-mengatasi-nyerisaat-menstruasi\#ixzz3Jaahza1R. Diakses 20 November 2014; 2014.

7. Sloane, Ethel. Anatomi dan Fisiologi. Jakarta : EGC; 2003. 